\title{
VALIDITY OF ADMISSION TEST AS A SCREENING TEST IN DIFFERENTIATING HIGH AND LOW OBSERVATIONAL ANTENATAL WOMEN- A PROSPECTIVE STUDY IN A TERTIARY CARE HOSPITAL
}

\author{
Dhanalakshmi Kaliya Moorthy1, Vengadeswari Ramakrishnan² \\ ${ }_{1}^{1}$ Assistant Professor, Department of Obstetrics and Gynaecology, Government Villuppuram Medical College, Villuppuram. \\ ${ }^{2}$ Associate Professor, Department of Obstetrics and Gynaecology, Government Villuppuram Medical College, Villuppuram.
}

\section{ABSTRACT}

\section{BACKGROUND}

Non-stress test is a non-invasive test, most commonly used for the antepartum evaluation of foetal well-being. Admission cardiotocogram is usually a 20 mins. recording of foetal heart rate immediately after admission to labour ward. Abnormal tracing might indicate and identify potential foetal compromise at an early stage and allow early intervention. Admission test enable the obstetrician to concentrate more on those foetuses having abnormal tracings than those with reactive tracings.

\section{MATERIALS AND METHODS}

It is a prospective study of assessing the validity of admission test as a screening test to differentiate high and low observational antenatal women. The study was conducted at Institute of Social Obstetrics and Govt. Kasturba Gandhi Hospital, Triplicane, Chennai during the period of April 2007 to April 2008; 800 number of antenatal women who were admitted through casualty were taken for the study based on the inclusion and exclusion criteria. After eliciting the history and complete clinical examination of the patient, the admission test is performed on each patient for 20 minutes. The admission test tracings were typed into- (i) Reactive, (ii) Suspicious, (iii) Ominous. Depending on the type of tracings, the mode of management varies. Patient can be divided into low and high observational status depending upon the tracings.

\section{RESULTS}

In this study, the number of patients in the age group between 18 to 20 years were $80(10 \%), 21$ to 29 years were 600 patients (75\%) and the patients in 30 to 35 years were 120 (15\%). In this study, the patients in primi were 496 (62\%) and second gravida were 304 patients (38\%). Highest number of patients were primi. Among them 784 patients were booked ones and 16 were unbooked. The admission test tracing pattern was such as reassuring pattern in 481 patients, suspicious in 267 patients and ominous in 52 patients. CTG observational status was low in 481 (60.13\%) patients and it was high in 319 patients (39.87\%). Spontaneous labour occurs in 624 patients (78\%) and induced labour in 176 patients (22\%). Since "p" value is less than 0.05 , there is a significant correlation between type of tracings and mode of delivery. Among the total of 800 patients in this study, 380 $(47.5 \%)$ number of the patients had the spontaneous labour in the primi gravida and $116(14.5 \%)$ patients had the induced labour. In second gravida, it was about 244 patients (30.5\%) in spontaneous labour and 304 (38\%) were in induced labour; P value0.226; statistically no significant relationship exists between Gravida and type of Labour. In this study, APGAR score more than 7 patients were 561 number (70.1\%) and foetal outcome was good in 561 patients and it is poor in 239 patients. In this study the highest number of patients, 361 had the babies with birth weight of 2.4 to $2.7 \mathrm{Kgs}$.

\section{CONCLUSION}

The study shows that there is a good correlation between reactive tracings and good foetal outcome even with less frequent monitoring. Hence, the admission test can be used as a useful tool to differentiate between these two categories of women in early labour to maximally utilize the available limited man power.

\section{KEYWORDS}

Admission Test, Tracing Pattern, Antenatal.

HOW TO CITE THIS ARTICLE: Moorthy DK, Ramakrishnan V. Validity of admission test as a screening test in differentiating high and low observational antenatal women- a prospective study in a tertiary care hospital. J. Evolution Med. Dent. Sci. 2017;6(25): 2109-2116, DOI: $10.14260 /$ Jemds/2017/459

\section{BACKGROUND}

Non-stress test is a non-invasive test, most commonly used for the antepartum evaluation of foetal well-being. 1,2 The rationale underlying this test is that the presence of spontaneous foetal health rate accelerations with foetal movements is an indicator of foetal well-being.

Financial or Other, Competing Interest: None.

Submission 06-03-2017, Peer Review 18-03-2017,

Acceptance 20-03-2017, Published 27-03-2017.

Corresponding Author:

Dr. Dhanalakshmi Kaliya Moorthy,

\#No. 31, Brindhavan Street, Thenral Nagar East,

Thirumullaivayil, Chennai-600062.

E-mail:yuvadhans@gmail.com

DOI: $10.14260 /$ jemds $/ 2017 / 459$

Admission cardiotocogram is usually a 20 mins. recording of foetal heart rate immediately after admission to labour ward. Abnormal tracing might indicate and identity potential foetal compromise at an early stage and allow early intervention. ${ }^{3,4}$

Admission test enable the obstetrician to concentrate more on those foetuses having abnormal tracings than those with reactive tracings.

\section{Need for Admission Test}

In low resource setting, there is a need to segregate those antenatal women who require constant monitoring and those who can be monitored as usual. One of the low cost, easily available methods with long-term benefit is admission test. Though, the initial cost could be high, the recurring cost 
effectiveness of this test makes it an ideal tool to improve perinatal outcome.

\section{MATERIALS AND METHODS}

\section{Material/Foetal Monitor BT- 300 Consists of-}

1. BT 300 main body.

2. Ultrasound transducer (Doppler Probe).

3. The Co-Transducer (Uterine contraction probe).

4. Event marker.

5. Thermal print paper.

6. Power adapter.

7. Ultrasound gel.

8. Transducer belt.

\section{Type of Study}

It is a prospective study of assessing the validity of admission test as a screening test to differentiate high and low observational antenatal women.

\section{Place of Study}

The study was conducted at Institute of Social Obstetrics and Govt. Kasturba Gandhi Hospital, Triplicane, Chennai during the period of April 2007 to April 2008.

\section{Study Population}

800 antenatal women were selected based on inclusion and exclusion criteria.

\section{Inclusion Criteria}

1. Primi and Second gravida.

2. Singleton pregnancy.

3. Cephalic presentation.

4. No contraindications for vaginal delivery.

5. No Medical, Surgical, Obstetrical complications.

\section{Exclusion Criteria}

1. Multigravida.

2. Preeclampsia.

3. Gestational Diabetes Mellitus, Multiple pregnancies.

4. Abruptio placentae.

5. Heart disease complicating pregnancy.

6. Malpositions and Malpresentations.

7. Anaemia.

8. FGR- Foetal growth restriction.

9. Post Term.

\section{Non-Stress Test}

The pregnant mother was asked to empty her bladder and all the procedure, what to expect during the procedure and what is expected of her were explained to her. She is placed in the semi-Fowler's position. The ultrasound transducer is applied to the maternal abdomen with a gel interface and the foetal heart rate is observed for 20 mins. The patient was asked to press the event marker every time she perceives foetal movement. Presence of spontaneous foetal heart rate accelerations with foetal movement is an indicator of foetal well-being.

\section{Method of Study}

Antenatal women who are admitted through casualty were taken for the study based on the inclusion and exclusion criteria. After eliciting the history and complete clinical examination of the patient (both general and obstetrical) consent was obtained from each patient for admission test.
Before getting consent from the patients, the entire procedure is explained to her.

The admission test is performed on each patient for 20 minutes. The admission test tracings were typed into- (i) Reactive, (ii) Suspicious, (iii) Ominous. Depending on the type of tracings, the mode of management varies.

Patient can be divided into low and high observational status depending upon the tracings.

Low observational status- Reactive tracing.

High observational status- Suspicious + Ominous Tracings.

If the admission test tracings are reactive and not in immediate labour, she is transferred to antenatal ward. If the tracings are ominous, she is transferred to labour ward and further management is decided based on individual condition.

In suspicious tracings, the patient is transferred to I stage labour room. After giving intravenous hydration and nasal oxygen, the admission test is repeated after 30 minutes. If the repeat admission test is reactive, she is observed in the low observational unit.

When the repeat admission test is still suspicious, she is shifted to high observational unit and additional measures to monitor foetus are initiated. Necessary interventions are effective depending on individual outcome.

\section{NST Variables to be Evaluated are-}

- Baseline foetal heart rate.

- Variability of foetal heart rate.

- Presence or absence of accelerations.

- Presence or absence of decelerations.

\section{Normal, Reassuring or Reactive}

- $\quad$ Two or more accelerations (> 15 beats/min.) lasting for more than 15 secs.) in 20 minutes.

- Baseline foetal heart rate 110 - 150 beats/min

- Baseline variability 5 - 25 beats/min.

- Absence of decelerations.

- Moderate tachycardia/bradycardia and accelerations.

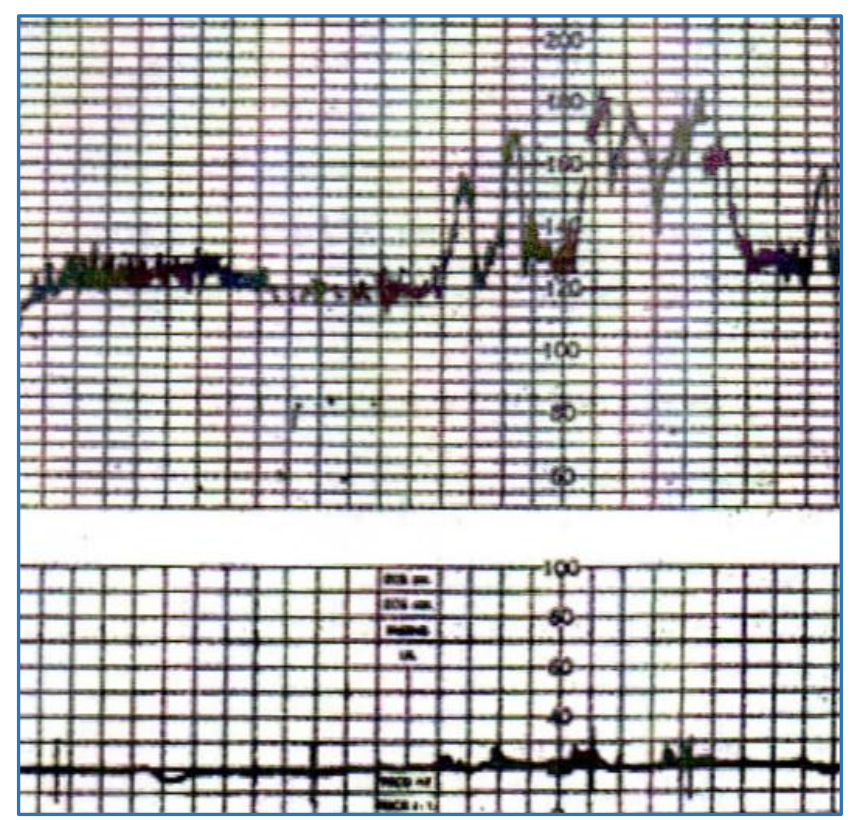

Figure 1. Reactive Trace with Acceleration Suspicious, Equivocal or Non-Reactive 
- Absence of accelerations.

- $\quad$ Reduced baseline variability ( 5 - 10 beats/min) for more than 40.

- Baseline bradycardia (FHR less than 100 beats/min or tachycardia (FHR more than 150 beats/min).

- Presence of decelerations.

- Variable decelerations depth $<60$ beats per min, duration $<60 \mathrm{sec}$.

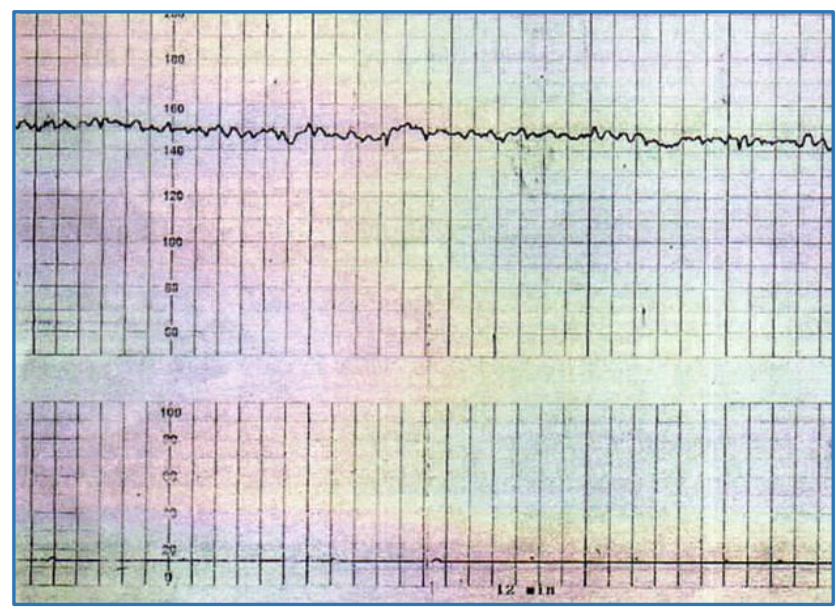

Figure 2. Suspicious: i) Baseline Heart Rate $>150$ bpm; ii) No Accelerations

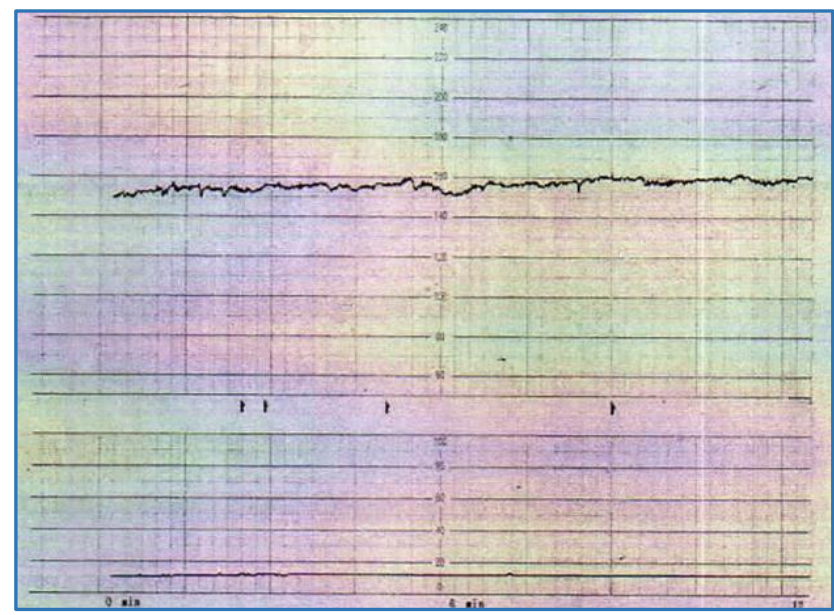

Figure 3. Suspicious: i) Baseline FHR $>150$ bpm; ii) No Accelerations

\section{Pathologic/Ominous}

- $\quad$ Silent pattern (5 beats/min) and baseline foetal heart rate $>150$ beats per min (or) $<110$ beats/min.

- No acceleration.

- Repeated late decelerations and/or complicated variable decelerations.

- $\quad$ Prolonged bradycardia (FHR $<100$ beats/min for more than 10 mins.).

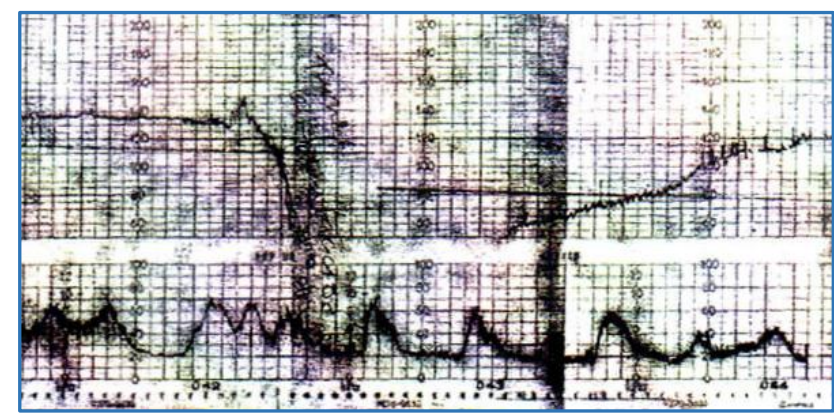

Figure 4. Ominous: i) Prolonged

Bradycardia; ii) No Accelerations

\section{Statistical Analysis}

The observed data was analysed by SPSS version 21.0 software. The collected data were tabulated and expressed as mean, standard deviation, numbers and percentages. Continuous variables were compared with sensitivity and specificity tests. The comparison was done using Chi-Square, as appropriate value reported at the $95 \%$ confidence interval. $P$ value $<0.05$ was considered as statistically significant.

\section{RESULTS}

In this study, the number of patients in the age group between 18 and 20 years were $80(10 \%), 21$ to 29 years were 600 patients $(75 \%)$ and the patients in 30 to 35 years were 120 (15\%). Shown in Figure 5.

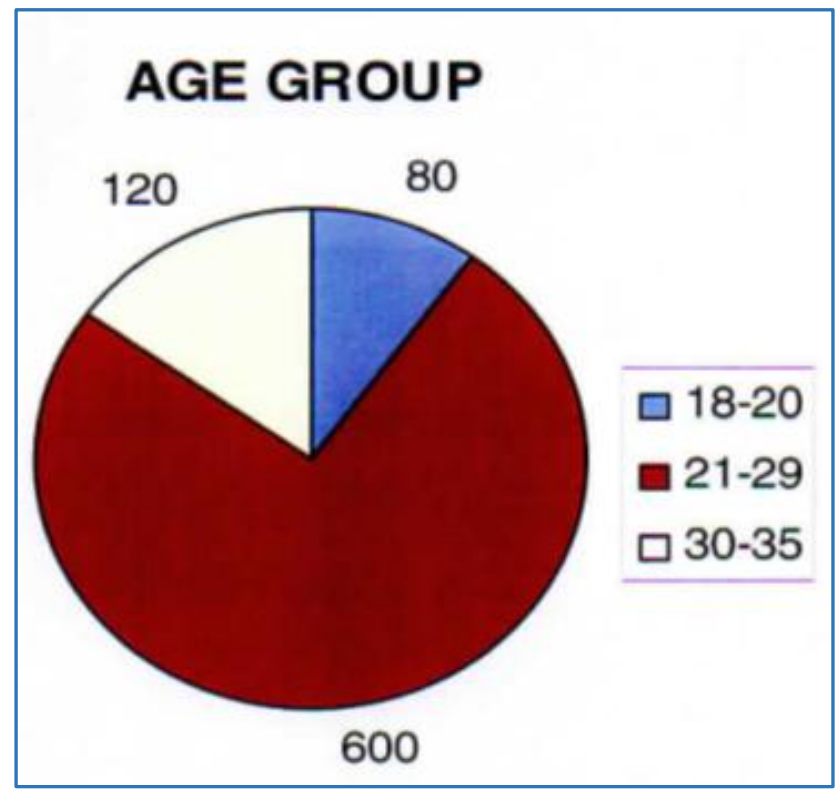

Figure 5

In this study, the patients in primi were $496(62 \%)$ and second gravida were 304 patients (38\%). Highest number of patient were primi as shown in Fig. 6. Among them 784 patients were booked ones and 16 were un-booked as shown in Table 1. 


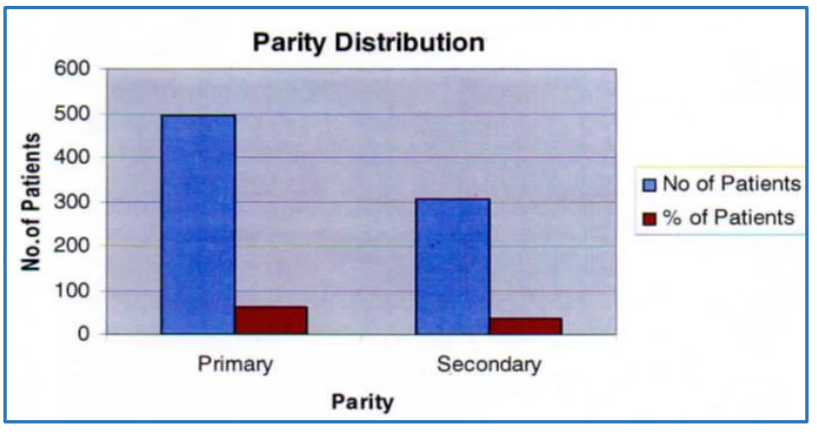

Figure 6

\begin{tabular}{|c|c|c|}
\hline Booking Status & No. of Patients & \% of Patients \\
\hline Booked & 784 & 98 \\
\hline Unbooked & 16 & 2 \\
\hline \multicolumn{3}{|c|}{ Table 1. Booking Status } \\
\hline
\end{tabular}

\section{Admission Test Trace Pattern}

Table number 4 shows the pattern such as reassuring pattern in 481 patients, suspicious in 267 patients and ominous in 52 patients, which is shown in Table 2. CTG observational status was low in $481(60.13 \%)$ patients and it was high in 319 patients $(39.87 \%)$, which is shown in Table 3.

\begin{tabular}{|c|c|c|}
\hline Tracings & No. of Patients & \% of Patients \\
\hline Reassuring & 481 & 60.1 \\
\hline Suspicious & 267 & 33.4 \\
\hline Ominous & 52 & 6.5 \\
\hline \multicolumn{2}{|r|}{ Table 2. Admission Test Trace Pattern } \\
\hline
\end{tabular}

\begin{tabular}{|c|c|c|}
\hline Observational Status & No. of Patients & \% of Patients \\
\hline Low & 481 & 60.13 \\
\hline High & 319 & 39.87 \\
\hline \multicolumn{2}{|c|}{ Table 3. CTG Observational Status } \\
\hline
\end{tabular}

Spontaneous labour occurs in 624 patients (78\%) and induced labour in 176 patients $(22 \%)$ shown in Table 4 and mode of delivery was shown in Table 5 .

\begin{tabular}{|c|c|c|}
\hline Type of Labour & No. of Patients & \% of Patients \\
\hline Spontaneous & 624 & 78 \\
\hline Induced & 176 & 22 \\
\hline \multicolumn{3}{|c|}{ Table 4. Type of Labour } \\
\hline
\end{tabular}

\begin{tabular}{|c|c|c|}
\hline Mode of Delivery & No. of Patients & \% of Patients \\
\hline SVD & 545 & 68.1 \\
\hline IVD & 80 & 10 \\
\hline CS & 175 & 21.9 \\
\hline \multicolumn{2}{|c|}{ Table 5. Mode of Delivery } \\
\hline
\end{tabular}

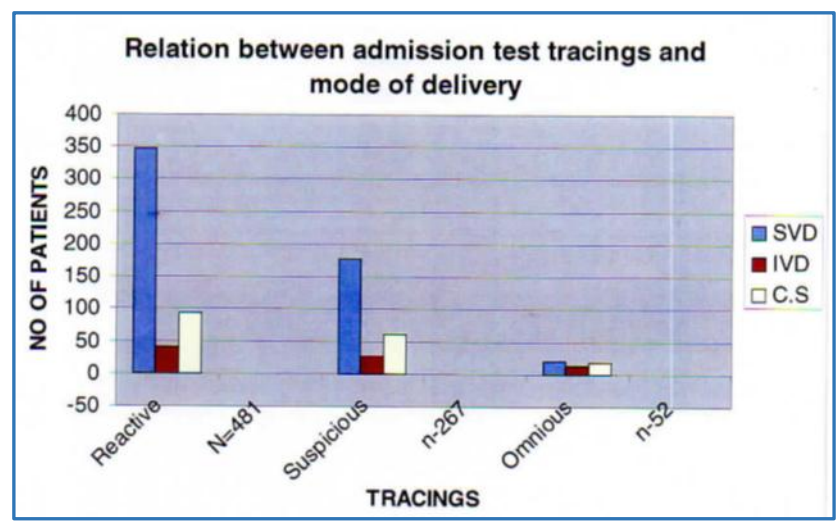

Figure 7

\begin{tabular}{|c|c|c|c|c|}
\hline \multirow{2}{*}{ Tracings } & \multicolumn{3}{|c|}{ Mode of Delivery } & \multirow{2}{*}{ Total } \\
\cline { 2 - 4 } & SVD & IVD & CS & \\
\hline Reactive & 347 & 40 & 94 & 481 \\
$\mathrm{n}=481$ & $(43.4 \%)$ & $(5.0 \%)$ & $(11.8 \%)$ & $(60.1 \%)$ \\
\hline Suspicious & 178 & 27 & 62 & 267 \\
$11-267$ & $(22.3 \%)$ & $(34 \%)$ & $(7.8 \%)$ & $(33.4 \%)$ \\
\hline Ominous & 20 & 13 & 19 & 52 \\
$\mathrm{n}-52$ & $(2.5 \%)$ & $(1.6 \%)$ & $(2.4 \%)$ & $(6.5 \%)$ \\
\hline \multirow{2}{*}{ Total } & $\mathbf{5 4 5}$ & $\mathbf{8 0}$ & $\mathbf{1 7 5}$ & $\mathbf{8 0 0}$ \\
& $(\mathbf{6 8 . 1 2} \%)$ & $(10 \%)$ & $(\mathbf{2 1 . 8 8} \%)$ & $(\mathbf{1 0 0 \% )}$ \\
\hline \multicolumn{4}{|c|}{ Table 6. Relation between Admission } \\
Test Tracings and Mode of Delivery \\
\hline
\end{tabular}

\begin{tabular}{|c|c|c|}
\hline Mode of Delivery & No. of Patients & \% of Patients \\
\hline SVD & 545 & 68.1 \\
\hline IVD & 80 & 10 \\
\hline CS & 175 & 21.9 \\
\hline \multicolumn{2}{|c|}{ Table 7. Mode of Delivery } \\
\hline
\end{tabular}

Relation between admission test tracing and the mode of delivery was shown in Table 6, Figure 7. As per reason, ChiSquare test $P$ value $=0.000$ since " $p$ " value is less than 0.05 there is a significant correlation between type of tracings and mode of delivery.

\begin{tabular}{|c|c|c|c|}
\hline \multirow{2}{*}{ Gravida } & \multicolumn{2}{|c|}{ Type of Labour } & \multirow{2}{*}{ Total } \\
\cline { 2 - 3 } & Spontaneous & Induced & \\
\hline Primi & $380(47.5 \%)$ & $116(14.5 \%)$ & $496(62 \%)$ \\
\hline Second & $244(30.5 \%)$ & $60(7.5 \%)$ & $304(38 \%)$ \\
\hline Total & $\mathbf{6 2 4}(\mathbf{7 8 . 0} \%)$ & $\mathbf{1 7 6}(\mathbf{2 2 . 0 \% )}$ & $\mathbf{8 0 0}(\mathbf{1 0 0 . 0 \% )}$ \\
\hline \multicolumn{2}{|c|}{ Table 8. Between Gravida and Type of Labour } \\
\hline
\end{tabular}

Among the total of 800 patients in this study, 380 $(47.5 \%)$ number of the patients had the spontaneous labour in the primi gravida and $116(14.5 \%)$ patients had the induced labour.

In second gravida, it was about 244 patients (30.5\%) in spontaneous labour and 304 (38\%) were in induced labour, which was shown in Table 8.

As per chi square test, $\mathrm{p}$ value- 0.226 statistically no significant relationship exists between Gravida and type of Labour.

\begin{tabular}{|c|c|c|c|}
\hline \multirow{2}{*}{$\begin{array}{c}\text { Type of } \\
\text { Labour }\end{array}$} & \multicolumn{3}{|c|}{ Mode of Delivery } \\
\cline { 2 - 4 } & SVD & IVD & CS \\
\hline Spontaneous & $425(53.1 \%)$ & $60(7.5 \%)$ & $139(17.4 \%)$ \\
\hline Induced & $120(15.0 \%)$ & $20(2.5 \%)$ & $36(4.5 \%)$ \\
\hline \multicolumn{3}{|c|}{ Table 9. Type of Labour vs. Mode of Delivery } \\
\hline
\end{tabular}

Labour vs. mode of delivery was shown in Table 9. In this study among the spontaneous on set of labour, spontaneous vaginal delivery were 425 patients (53.1\%), induced vaginal delivery were 60 patients and caesarean sections were in 139 (17.7\%) number of cases. In induced labour, the spontaneous vaginal deliveries were $120(15.0 \%)$ number of cases, induced deliveries were $20(2.5 \%)$ numbers and caesarean was in $36(4.5 \%)$ cases.

$P$ value $=0.731$, since $p$ value $>0.05$ there is no significant relationship between type of labour and mode of delivery. 


\begin{tabular}{|c|c|c|c|c|}
\hline \multirow{2}{*}{ Gravida } & \multicolumn{3}{|c|}{ Mode of Delivery } & \multirow{2}{*}{ Total } \\
\cline { 2 - 4 } & SVD & IVD & CS & \\
\hline \multirow{2}{*}{ Primi } & 361 & 54 & 81 & 496 \\
& $(45.1 \%)$ & & $(10.17 \%)$ & $(62.0 \%)$ \\
\hline \multirow{2}{*}{ Second } & 184 & 26 & 94 & 304 \\
& $(23.0 \%)$ & $(3.3 \%)$ & $(11.8 \%)$ & $(38.0 \%)$ \\
\hline \multirow{2}{*}{ Total } & $\begin{array}{c}\mathbf{5 4 5} \\
(\mathbf{6 8 . 1 \% )}\end{array}$ & $\begin{array}{c}\mathbf{8 0} \\
(\mathbf{1 0 . 0} \%)\end{array}$ & $\begin{array}{c}\mathbf{1 7 5} \\
(\mathbf{2 1 . 9 \% )}\end{array}$ & $\begin{array}{c}\mathbf{8 0 0} \\
(\mathbf{1 0 0 . 0 \% )}\end{array}$ \\
\hline \multicolumn{4}{|c|}{ Table 10. Gravida vs. Mode of Delivery } \\
\hline
\end{tabular}

Gravida vs. mode of delivery was shown in Table 10. As per Chi Square test $p$ value $=0.000$, so the association between these two variables is statistically significant.

The APGAR score and its percentage, the foetal outcome were shown in Table 11 and 12.

\begin{tabular}{|c|c|c|}
\hline APGAR Score & No. & Percent \\
\hline Less than 4 & 67 & $8.4 \%$ \\
\hline $4-6$ & 172 & $21.5 \%$ \\
\hline More than 7 & 561 & $70.1 \%$ \\
\hline \multicolumn{2}{|c|}{ Table 11. APGAR Score } \\
\hline
\end{tabular}

\begin{tabular}{|c|c|c|}
\hline Foetal Outcome & No & Percent \\
\hline Good & 561 & $70.1 \%$ \\
\hline Poor & 239 & $29.9 \%$ \\
\hline \multicolumn{2}{|c|}{ Table 12. Foetal Outcome } \\
\hline
\end{tabular}

Admission test tracing correlation with APGAR score and admission test tracing with foetal outcome were shown in Table 13 and Table 14, respectively. In this study, APGAR score more than 7 patients were 561 in number $(70.1 \%)$ and foetal outcome was good in 561 patients and it is poor in 239 patients.

\begin{tabular}{|c|c|c|c|c|}
\hline \multirow{2}{*}{$\begin{array}{c}\text { Admission } \\
\text { Test } \\
\text { Tracings }\end{array}$} & \multicolumn{3}{|c|}{ APGAR } & \multirow{2}{*}{ TOTAL } \\
\hline & $<4$ & $4-6$ & $>7$ & \\
\hline Reactive & $\begin{array}{c}12 \\
(1.5 \%)\end{array}$ & $\begin{array}{c}59 \\
(7.4 \%)\end{array}$ & $\begin{array}{c}410 \\
(51.3 \%)\end{array}$ & $\begin{array}{c}481 \\
(60.1 \%)\end{array}$ \\
\hline Suspicious & $\begin{array}{c}30 \\
(3.8 \%)\end{array}$ & $\begin{array}{c}98 \\
(12.3 \%)\end{array}$ & $\begin{array}{c}139 \\
(17.4 \%)\end{array}$ & $\begin{array}{c}267 \\
(33.4 \%)\end{array}$ \\
\hline Ominous & $\begin{array}{c}25 \\
(3.1 \%)\end{array}$ & $\begin{array}{c}15 \\
(1.9 \%)\end{array}$ & $\begin{array}{c}12 \\
(1.5 \%)\end{array}$ & $\begin{array}{c}52 \\
(6.5 \%)\end{array}$ \\
\hline Total & $\begin{array}{c}67 \\
(8.4 \%)\end{array}$ & $\begin{array}{c}172 \\
(21.5 \%)\end{array}$ & $\begin{array}{c}561 \\
(70.1 \%)\end{array}$ & $\begin{array}{c}800 \\
(100.0 \%)\end{array}$ \\
\hline
\end{tabular}

Table 13. Admission Test Tracings vs. APGAR Score $\mathrm{P}$ value $=0.002$.

Since $p$ value is $<0.05$, there is a statistically significant correlation between admission test tracings and APGAR.

\begin{tabular}{|c|c|c|c|}
\hline & \multicolumn{2}{|c|}{ Foetal Outcome } & Total \\
\hline $\begin{array}{c}\text { Admission } \\
\text { Test Tracing }\end{array}$ & Good & Poor & $48(60.1 \%)$ \\
\hline Reactive & $410(51.3 \%)$ & $71(8.9 \%)$ & $467(33.4 \%)$ \\
\hline Suspicious & $139(17.4 \%)$ & $128(16.0 \%)$ & 267 \\
\hline Ominous & 12 & 40 & $52(65.0 \%)$ \\
\hline Total & $561(70.1 \%)$ & $239(29.9 \%)$ & $800(100.0 \%)$ \\
\hline Table 14. Admission Test Tracings vs. Foetal Outcome \\
\hline
\end{tabular}

As per Pearson Chi-square test, $\mathrm{p}$ value $=0.002$. Abnormal CTG tracings are associated with poor foetal outcome than reactive tracings.

\begin{tabular}{|c|c|c|c|c|}
\hline \multirow{2}{*}{$\begin{array}{l}\text { Mode of } \\
\text { Delivery }\end{array}$} & \multicolumn{3}{|c|}{ APGAR } & \multirow{2}{*}{ Total } \\
\hline & $<4$ & $4-6$ & $>7$ & \\
\hline \multirow[t]{2}{*}{ SVD } & $37(4.6 \%)$ & $\begin{array}{c}119 \\
(14.9 \%)\end{array}$ & $\begin{array}{c}389 \\
(48.6 \%)\end{array}$ & $\begin{array}{c}545 \\
(68.1 \%)\end{array}$ \\
\hline & $\begin{array}{c}11 \\
\left(\mathrm{I} .4^{\circ} / 0\right)\end{array}$ & $\begin{array}{c}14 \\
(1.8 \%)\end{array}$ & $\begin{array}{c}55 \\
(6.9 \%)\end{array}$ & $\begin{array}{c}80 \\
(10.0 \%)\end{array}$ \\
\hline CS & $\begin{array}{c}19 \\
(2.4 \%)\end{array}$ & $\begin{array}{c}39 \\
(4.9 \%)\end{array}$ & $\begin{array}{c}117 \\
(14.6 \%)\end{array}$ & $\begin{array}{c}175 \\
(21.9 \%)\end{array}$ \\
\hline Total & $\begin{array}{c}67 \\
(8.4 \%)\end{array}$ & $\begin{array}{c}172 \\
(21.5 \%)\end{array}$ & $\begin{array}{c}561 \\
(70.1 \%)\end{array}$ & $\begin{array}{c}800 \\
(100.0 \%)\end{array}$ \\
\hline
\end{tabular}

As per chi-square test $\mathrm{P}$ value $=0.149$.

\begin{tabular}{|c|c|c|c|}
\hline \multirow{2}{*}{$\begin{array}{c}\text { Mode of } \\
\text { Delivery }\end{array}$} & \multicolumn{2}{|c|}{ Foetal Outcome } & \multirow{2}{*}{ Total } \\
\cline { 2 - 3 } SVD & $\begin{array}{c}\text { Good } \\
(489\end{array}$ & $\begin{array}{c}\text { Poor } \\
156 \\
(19.5 \%)\end{array}$ & $\begin{array}{c}545 \\
(68.1 \%)\end{array}$ \\
\hline \multirow{2}{*}{ IVD } & 55 & 25 & 80 \\
& $(6.9 \%)$ & $(3.1 \%)$ & $(10.0 \%)$ \\
\hline \multirow{2}{*}{ CS } & 117 & 58 & 175 \\
& $(14.60 / 0)$ & $(7.3 \%)$ & $(21.9 \%)$ \\
\hline \multirow{2}{*}{ Total } & $\begin{array}{c}\mathbf{5 6 1} \\
\text { (70.1\%) }\end{array}$ & $\begin{array}{c}\mathbf{2 3 9} \\
\mathbf{( 2 9 . 9 \% )}\end{array}$ & $\begin{array}{c}\mathbf{8 0 0} \\
\mathbf{( 1 0 0 . 0 \% )}\end{array}$ \\
\hline \multicolumn{2}{|c|}{ Table 16. Mode of Delivery and Foetal Outcome } \\
\hline
\end{tabular}

As per chi-square test, $\mathrm{P}$ value $=0.054$.

\begin{tabular}{|c|c|c|}
\hline Birth Weight & Frequency & Percent \\
\hline $2.4-2.7$ & 349 & 43.62 \\
\hline $2.8-3.1$ & 245 & 30.63 \\
\hline $3.2-3.4$ & 206 & 25.75 \\
\hline \multicolumn{3}{|c|}{ Table 17. Birth Weight } \\
\hline
\end{tabular}

\begin{tabular}{|c|c|c|c|c|}
\hline \multirow{2}{*}{$\begin{array}{c}\text { Birth } \\
\text { Weight (kg) }\end{array}$} & \multicolumn{3}{|c|}{ Mode of Delivery } & \multirow{2}{*}{ TOTAL } \\
\hline & SVD & IVD & $\mathrm{CS}$ & \\
\hline $2.4-2.7$ & $\begin{array}{c}239 \\
(29.8 \%)\end{array}$ & $\begin{array}{c}36 \\
(4.5 \%)\end{array}$ & $\begin{array}{c}74 \\
(9.25 \%)\end{array}$ & $\begin{array}{c}349 \\
(43.62 \%)\end{array}$ \\
\hline $2.8-3.1$ & $\begin{array}{c}172 \\
(21.5 \%)\end{array}$ & $\begin{array}{c}23 \\
(2.87 \%)\end{array}$ & $\begin{array}{c}50 \\
(6.25 \%)\end{array}$ & $\begin{array}{c}245 \\
(30.63 \%)\end{array}$ \\
\hline $3.2-3.4$ & $\begin{array}{c}134 \\
(16.75 \%)\end{array}$ & $\begin{array}{c}21 \\
(2.62 \% \\
\end{array}$ & $\begin{array}{c}51 \\
(6.38 \%)\end{array}$ & $\begin{array}{c}206 \\
(25.75 \%)\end{array}$ \\
\hline Total & $\begin{array}{c}545 \\
(68.13 \%)\end{array}$ & $\begin{array}{c}80 \\
(10 \%)\end{array}$ & $\begin{array}{c}175 \\
(21.87 \%)\end{array}$ & $\begin{array}{c}800 \\
(100.0 \%)\end{array}$ \\
\hline
\end{tabular}

As per chi-square test, $\mathrm{P}$ value $=0.996$.

\begin{tabular}{|c|c|c|c|c|}
\hline \multirow{2}{*}{$\begin{array}{c}\text { Birth } \\
\text { Weight }\end{array}$} & \multicolumn{3}{|c|}{ APGAR } & \multirow{2}{*}{ TOTAL } \\
\hline & $<4$ & $4-6$ & $>7$ & \\
\hline $2.4-2.7$ & $\begin{array}{c}36 \\
(4.5 \%)\end{array}$ & $\begin{array}{c}70 \\
(8.75 \%)\end{array}$ & $\begin{array}{c}243 \\
(30.38 \%)\end{array}$ & $\begin{array}{c}349 \\
(43.62 \%)\end{array}$ \\
\hline $2.8-3.1$ & $\begin{array}{c}15 \\
(1.88 \%)\end{array}$ & $\begin{array}{c}59 \\
(7.38 \%)\end{array}$ & $\begin{array}{c}171 \\
(21.38 \%)\end{array}$ & $\begin{array}{c}245 \\
(30.63 \%)\end{array}$ \\
\hline $3.2-3.4$ & $\begin{array}{c}16 \\
(2 \%)\end{array}$ & $\begin{array}{c}43 \\
(5.38 \%)\end{array}$ & $\begin{array}{c}147 \\
(18.38 \%)\end{array}$ & $\begin{array}{c}206 \\
(25.75)\end{array}$ \\
\hline Total & $\begin{array}{c}67 \\
(8.38 \%)\end{array}$ & $\begin{array}{c}172 \\
(21.5 \%)\end{array}$ & $\begin{array}{c}561 \\
(70.12 \%)\end{array}$ & $\begin{array}{c}800 \\
(100.0 \%)\end{array}$ \\
\hline
\end{tabular}

As per chi-square test, $\mathrm{P}$ value $=0.074$. 


\begin{tabular}{|c|c|c|c|}
\hline \multirow{2}{*}{$\begin{array}{c}\text { Birth Weight } \\
\text { (kg) }\end{array}$} & \multicolumn{2}{|c|}{ Foetal Outcome } & \multirow{2}{*}{ Total } \\
\hline & Good & Poor & \\
\hline $2.4-2.7$ & $\begin{array}{c}243 \\
(30.38 \%)\end{array}$ & $\begin{array}{c}106 \\
(13.25 \%)\end{array}$ & $\begin{array}{c}349 \\
(43.63 \%)\end{array}$ \\
\hline $2.8-3.1$ & $\begin{array}{c}171 \\
(21.38 \%)\end{array}$ & $\begin{array}{c}74 \\
(9.25 \%)\end{array}$ & $\begin{array}{c}245 \\
(30.62 \%)\end{array}$ \\
\hline $3.2-3.4$ & $(18.38 \%)$ & $\begin{array}{c}59 \\
(7.38 \%)\end{array}$ & $\begin{array}{c}206 \\
(25.75 \%)\end{array}$ \\
\hline Total & $\begin{array}{c}561 \\
(70.13 \%)\end{array}$ & $\begin{array}{c}239 \\
(29.87 \%)\end{array}$ & $\begin{array}{c}800 \\
(100.0 \%)\end{array}$ \\
\hline
\end{tabular}

As per chi-square test, $\mathrm{P}$ value $=0.871$.

\begin{tabular}{|c|c|}
\hline Sensitivity *. & $70.29 \%$ \\
\hline Specificity *- & $73.08 \%$ \\
\hline Positive Predictive Value .* & $52.66 \%$ \\
\hline Negative Predictive Value .* & $85.24 \%$ \\
\hline Diagnostic Accuracy .* & 7225 \\
\hline \multicolumn{2}{|c|}{ Table 21. Admission Test Evaluation } \\
\hline
\end{tabular}

\section{DISCUSSION}

In this study, 800 antenatal women were included. Majority of the antenatal women were primi, belonging to the age group 21 - 29 years.

This is in accordance with more pregnancies in particular age group.

Regarding booking status of the patients (Table 3) in this study, 98\% (11 - 784) of women were booked. Only 2\% (n 16) were unbooked. Most of the unbooked patients were second gravida. Booking status has no significance in this study.

\section{Discussion on Table 4}

In this study, out of 800 AN women 481 (60.1\%) of patients had reactive admission test tracings; $33.4 \%$ (11 - 267) belonged to suspicious tracings group and $6.5 \%$ (n- 52) belonged to ominous group.

In 2002, Kasthugai $\mathrm{P}$ and Narogoni S conducted a study on Admission test- an effective risk screening tool with 500 patients. The tracings were: $86.6 \%(\mathrm{n}-433)$ had reactive $7.4 \%$ (n- 37) belonged to suspicious group and $0.6 \%(n-30)$ belonged to ominous.5,6,7

In Kandan Karibu Hospital, Singapore (1998), a study was conducted in 1000 Antenatal women for admission test in high and low-risk pregnancy.8,9 The tracings were reactive 982 (4.3\%), suspicious 49 (4.7\%) and ominous 10 (1\%).

\section{The CTG Observational Status of Antenatal Women (Table 5)}

In this study, $481(60.13 \%)$ patients belonged to low observational status and 319 (39.81\%) belonged to high observational status. The continuation of change over status patients will be discussed later.

\section{Type of Labour (Table 6)}

In the present study, $78 \%$ of labourers were spontaneous on set (n- 624). Only 22\% were induced type (11 - 176).

\section{Discussion on Table 8}

MacDonald et al conducted a randomised trial on admission cardiotocography in 1000 antenatal women (1985). ${ }^{10,11}$ Mode of delivery among them: SVD- 31\%, IVD- 9\%, CS- $60 \%$. Most of the caesarean deliveries occurred in abnormal CTG group. They found a statistically significant relation between nonreactive tests and increased incidence of IVD and CS (P < 0.05).

Ingemarsson et al (1986) carried out a study in $1000 \mathrm{AN}$ women on efficacy of admission test in predicting neonatal outcome, their mode of delivery. 12,13 SVD- $45 \%$, IVD- $6 \%$ and CS- $49 \%$. They also found that abnormal admission test tracings were associated with increased caesarean delivery than reactive tracings group $(\mathrm{p}<0.04)$.

In a study conducted by Vinitha Das, GK Malik in $170 \mathrm{AN}$ women on efficacy of admission test in predicting foetal jeopardy in labour, $60.97 \%$ of the abnormal tracings group had caesarean delivery. ${ }^{14}$ In reactive tracings group, only $45.7 \%$ of patients had caesarean delivery. They observed a significant relation between admission test tracings and mode of delivery ( $\mathrm{p}$ value- 0.04 ).

In this study, mode of delivery among 800 AN women$68.1 \%$-SVD, 10\% -IVD, $21.9 \%$-CS. On comparing admission test tracings with mode of delivery, only $19.5 \%(n-94)$ of the reactive group had caesarean delivery, but $23.22 \%(n-62)$ of suspicious and $36.53 \%(n-19)$ of the ominous group had caesarean delivery. This showed that abnormal tracings were associated with increased incidence of caesarean delivery than reactive tracings $(\mathrm{p}<0.05)$.

Kidd LC, Patel NB, Smith R did a randomised clinical trial on non-stress antenatal cardiography in 396 AN women in 1985.15,16,17 They found that caesarean delivery rates were almost same in both reactive and non-reactive tracings; hence, they concluded that availability of non-stress cardiotocography was not associated with increased labour induction (or) caesarean section.

\section{Discussion on Table 9}

In this study when gravida and type of labour were analysed, there was no significant association between them,18 (p 0.245). In a study by Mires G, Williams et al (2000) on admission test in low risk obstetric population, most of the second gravida were delivered by labour natural of spontaneous onset when they were analysed. There occurred significant association $(\mathrm{p}<0.01)$.

\section{Discussion on Table 10}

In this study primi: out of 496 AN women, 361 were delivered by normal vaginal delivery, 54 by Instrumental vaginal delivery and 81 by caesarean section. Among second gravida (11 - 304), 184 patients delivered naturally, 26 patients delivered by Instrumental vaginal delivery and 94 were delivery by Caesarean section. Since $p$ value $=0.000$, the relation between these two is statistically significant.

In a study conducted by Nidhikatya (2000) in 1000 AN women, no association existed between parity and mode of delivery $(\mathrm{p}=0.226)$.

\section{Discussion on Table 14}

Atul K Sood did a study in 500 AN women on evaluation of non-stress test in low risk pregnancy. ${ }^{19,20}$ They found that 5 mins. APGAR score $<7$ and neonatal admissions were more commonly associated with non-reactive tracings than reactive tracings $(\mathrm{p}<0.005)$.

Sandal J et al and Gourounti did a study on effect of admission test on rate of CS, instrumental vaginal delivery 
and neonatal APGAR score. ${ }^{21,22}$ The relative risk for having a caesarean delivery (RR 1.2, CI 1.00 - 1.41) and instrumental delivery (RR 1\%, CI 1.00 - 1.18) were both high in abnormal tracings group. Similarly, the relative risk for low APGAR $(<7$ at 5 mins.) was also high in abnormal tracings group (RR 1.35, CI 0.85 - 2.13). They concluded that abnormal (Suspicious and Ominous) admission test tracings were associated with increased risk of instrumental vaginal delivery and caesarean section and low 5 mins. Apgar score.

Fawole AO, Sotiloye OS did a study on antenatal cardiotocography in $300 \mathrm{AN}$ women in Nigeria.23,24 They analysed that low APGAR $<7$ occurred most commonly in non-reactive tracings $(p=0.04)$. Reactive test was associated with 3-fold reduction in the incidence of low APGARS compared with non-reactive.

In 1989 Manterola Alvarez D, Angeles Weintraub conducted a study on admission test and perinatal outcome. ${ }^{25,26}$ They found a statistical significant correlation between suspicious and ominous tracings and foetal condition at birth (APGAR < 7) $\mathrm{p}=0.01$.

Pattison N, McCowan L did a study to assess the effects of antenatal cardiotocography on perinatal morbidity and mortality in 2000.27,28 No significant correlation existed between type of tracings and perinatal morbidity and mortality $(\mathrm{p}=0.18)$.

In 1984, a randomised controlled trial was conducted on admission test by Kidd LC and Smith R. In their study, they observed that frequency of intrapartum foetal distress and low APGAR score were similar in both reactive and abnormal tracings group.

In this study 40 babies of ominous tracings group 128 babies of suspicious group had APGAR score $<7$, but only 71 babies of the reactive tracings group had low APGAR score of $<7$. So abnormal tracings had 2-fold increased risk of having low APGAR score, then reactive tracings. (p value- 0.002) as discussion on Table 15.

Fawole AO and Sotiloye OS did a study on antenatal cardiotocography (2007) on $150 \mathrm{AN}$ women. They found that non-reactive test was strongly associated with poor foetal outcome $(p=0.04)$. They concluded that antenatal cardiotocography can be used in low resource settings for improving perinatal care.

Manterola Alvarez and Angeles Weintraub did a study on admission test and foetal outcome (1989). ${ }^{29}$ They took 600 Antenatal patients, observed that non-reactive tracings were significantly associated with increased risk of instrumental vaginal delivery, caesarean section and poor foetal outcome than reactive tracings group $(\mathrm{p}=0.03)$.

Pattison $\mathrm{N}$ and McCowan L did a study to assess the effects of cardiotocography on perinatal morbidity and mortality. They noted no significant effect of antenatal cardiotocography on perinatal outcome $(p=0.14)$.

In the study conducted by Kidd LC and Smith R on antenatal cardiotocography in 396 antenatal patients (1985) there was no difference in foetal outcome of reactive and non-reactive group.

Murphy J and Sheilo did a randomised controlled trial on admission cardiotocography in 8000 antenatal women (2002). They observed no difference in foetal outcome between usual care group and admission cardiotocography (RR 1.01, 95\%, CI > $0.70-1.47$ ). They concluded that routine use of cardiotocography for 20 mins. on admission to delivery does not improve foetal outcome.

In this study when admission test tracings and foetal outcome were analysed, the results showed that abnormal tracings associated with poor foetal outcome than reactive tracings $(\mathrm{p}=0.002)$ and $4 \%(\mathrm{n}=21)$ antenatal women, who were initially in low observational status switch over to high observational status later.

\section{In this Study, Diagnostic (or) Screening Test Evaluation} shows (Table 22)

- Sensitivity- 70.29\%.

- $\quad$ Specificity- $73.08 \%$.

- $\quad$ Positive predictive value- 52.66 .

- $\quad$ Negative predictive value- 85.24 .

- Diagnostic accuracy- $72.25 \%$.

\section{In a Study conducted by Atul $K$ Sood in 2002 on Admission Test showed \\ - Sensitivity- $41 \%$ \\ - Specificity- $94 \%$ \\ - $\quad$ PPV- $83 \%$ \\ - $\quad$ NPV- $72 \%$ \\ - Diagnostic accuracy- $74 \%$}

In 2001, Vinitha Das conducted a prospective randomised study on efficacy of admission test in predicting foetal distress. She observed-

- $\quad$ Sensitivity- $38 \%$

- $\quad$ Specificity- $79 \%$

- $\quad$ PPV- $48 \%$

- $\quad$ NPV- $72 \%$

In a study conducted by Kushtagi P (2002) on labour admission test showed-

- Sensitivity- $53 \%$

- $\quad$ Specificity- 93\%

- $\quad$ NPV- $91 \%$

The values obtained in the present study compares favourably with the values of other studies, indicating that reactive admission test correlates well with foetal well-being.

\section{CONCLUSION}

The present study was carried out at Institute of Social Obstetrics and Govt. Kasturba Gandhi Hospital, Chennai from April 2007 to April 2008, to analyse the efficacy of admission test as a predictor of observational status for women in early labour.

In settings with restricted man power and qualified staff, there is always a need to differentiate the patients who require constant monitoring and those who could be monitored less frequently. However, this differentiation could be arrived at only after an initial screening and such bifurcation.

In this study, $800 \mathrm{AN}$ women who were admitted to the labour ward of this tertiary care centre were selected based on the inclusion and exclusion criteria and after obtaining informed consent all of them were subjected to a 20 -minute admission test. Based on the findings of the admission test, they were divided into low observational status (reactive tracing) and high observational status (suspicious and/or 
ominous tracings). The onset, duration and mode of delivery along with the maternal and foetal outcome were analysed.

The study shows that there is a good correlation between reactive tracings and good foetal outcome even with less frequent monitoring. Hence, the admission test can be used as an useful tool to differentiate between these two categories of women in early labour to maximally utilise the available limited man power.

\section{REFERENCES}

[1] Weintraub ACD, Alonso A. To evaluate effectiveness of NST in identification of foetus under risk. Gynaecol Obstet Max 1989;57:3-7.

[2] Arul Kumaran ASI, Ingermasson S. Montar Traces of you: Clinician's guide to foetal trace interpretation. Boblingen; Hewlett Packard GMBH 1995:5965-6246.

[3] Sood AK. Evaluation of non stress test in high risk pregnancy. J Obstet Gynecol Ind 2002;52:71-5.

[4] Blix E, Oian P. Labour admission test: an assessment test: an assessment of test's value as screening for fetal distress in labour. Acta Obstet Gynecol Scand 2001;80(8):738-43.

[5] Brown VA, Sawers RS, Parsons RJ, et al. Value of antental cardiotocography in management of high risk pregnancy: a randomized controlled trial. Br J Obstet Gynaecol 1982;89(9)716-22.

[6] Breuker KH, Kusche M, Muller U, et al. The importance of antepartum cardiotocography. J Perinat Med 1986:14(3):171-9.

[7] Oats JN, Chew FT, Ratten VJ. Antepartum cardiotocography - an audit. Aust Obstet Gynaecol 1987;27(2):82-6.

[8] Emmen L, Huisjes HJ, Aarnoudse JG, et al. Antepartum diagnosis of the terminal fetal state by cardiotocography. $\mathrm{Br} \quad \mathrm{J}$ Obstet Gynaecol 1975;82(5):353-9.

[9] Fawole AO, Sotiloye OS, Oladimeji AO, et al. Antental cardiotocography: experience in a Nigerian tertiary hospital. Niger Postgrad Med J 2008;15(1):19-23.

[10] Gourounti K, Sandall J. Admission cardiotocography versus intermittent auscultation of fetal heart rate; Effects on neonatal apgar score, on rate of caesarean sections and on rate of instrumental delivery: a systematic review. Int J Nurs Stud 2007;44(6):102935.

[11] Impey L, Reynolds M, MacQuillan K, et al. Admission cardiotocography: a randomized controlled trial. Lancet 2003;361(9356):465-70.

[12] Ingemarsson I. Efficacy of admission test in predicting neonaltal outcome. Obstet Gyn 1986;68:800.

[13] Ingemarsson I, Arulkumaran S, Ingemarsson E, et al. Admission test: a screening test for fetal distress in labour. Obstet Gynecol 1986;68(6):800-6.
[14] Ingemarsson I, Arulkumaran S. The FHR Admission test. In fetal monitoring: Physiology and technique of antenatal and intrapartum fetal assessment. ed JAD spencer. Tunbridge wells: Castle House Publications 1989.

[15] Kelly J, Mansfield, Needham. Randomised controlled study of antepartum CTG. Br J Obstet Gynaecol 1982;89(6):427-33.

[16] Keane MW, Merger EO, Vice L. Effectiveness of nonstress test and perinatal outcome. Obstet 1981;57: 320.

[17] Kidd LC, Patel NB, Smith R. Non-stress antenatal cardiotocography - a prospective randomized clinical trial. Br J Obstet Gynaecol 1985;92(11):1156-9.

[18] Kushtagi P, Naragoni S. Labour admission test - an effective risk screening tool. J Indian Med Asso 2002;100(4):234-6.

[19] McCune GS, Doig J, Ridley W. Antepartum non-stress cardiotocogphy in high risk pregnancies. Br J Obstet Gynaecol 1983;90(8):697-704.

[20] Mirghani HM, Khair H. Comparison between visual and computerized cardiotocography in low risk pregnancy. Saudi Med J 2005;26(8):1228-30.

[21] Mires G, Williams F, Howie P. Randomised controlled trial of cardiotocography versus Doppler auscultation of fetal heart at admission in labour in low risk obstetric population. BMJ 2001;322(7300):1457-62.

[22] Murphy J, Sheil 0. Randomised controlled trial on Admission cardiotocography Lancet 2003;361(356): 465-70.

[23] Penning S, Garite TJ. Management of fetal distress. Management of fetal distress. Obstet Gynaecol Clin North Am 1999;26(2):259-74.

[24] Rooth G, Huch A, Huch R. FIGO News: guidelines for the use of fetal monitoring. Int J Gynaecol Obstet 1987;25:159-67.

[25] Sherer DM, Onyeije CI, Binder D, et al. Uncomplicated baseline fetal tachycardia or bradycardia in postterm pregnancies and perinaatal outcome. Am J Perinatol 1998;15(5):335-8.

[26] Solum T, Ingemarsson I, Sjoberg NO. Selection crtieria for antenatal cardiotocography. Z Geburtshilfe Perinatol 1979;183(3): 212-7.

[27] Das V, Katiyar N, Malik GK. Role of admission test. J Obstet Gynecol Ind 2001;51(1):48-50.

[28] Visser GH, Huisjes HJ. Diagnostic value of unstressed antepartum cardiotocogram. Br J Obstet Gynaecol 1977;84(5):321-6.

[29] Zuspan FP, Quilligan EJ, Iams JD, et al. Predictors of intrapartum fetal distress: the role of electronic fetal monitoring. Report of the National Institute of Child Health and Human Development Consensus Development Task Force. Am J Obstet Gynecol 1979;135(3):287-91. 